\title{
Comparison of the effects of different maize straw returning methods on saline soil improvement
}

\author{
Chen $\mathrm{Cai}^{1, \#}$,Yuan ChengPeng ${ }^{1, \#}$ \\ ${ }^{1}$ College of Resources and Environmental Sciences, China Agricultural University, 100193, China \\ \#These authors contributed equally to this work.
}

\begin{abstract}
Using corn straw as raw material, the effects of three different ways of returning corn straw to the field, namely direct returning corn straw to the field, decomposed corn straw returning to the field and maize straw biochar returning to the field, on saline-alkali soil were studied by indoor culture. The results showed that maize straw directly returned to the field was the best way to improve the stability of salinealkali soil aggregates; maize straw biochar returned to the field was the best way to reduce the alkalinity of saline-alkali soil; maize straw directly returned to the field and decomposed maize straw returned to the field enhanced the activity of soil urease and alkaline phosphatase, while reducing the activity of soil catalase. Maize straw biochar returned to field reduced soil urease activity and increased soil catalase activity, but had no significant effect on soil alkaline phosphatase activity.
\end{abstract}

\section{Introduction}

China is rich in crop straw resources. According to statistics, the main crop resources in 2016 in China amounted to 984 million tons, of which maize straw accounted for $41.92 \%$, which is the main source of straw[1]. Straw returning is a direct and effective way to utilize straw resources, which can be divided into direct returning and indirect returning. Direct returning refers to the direct application of untreated straw into the field; indirect returning refers to the chemical treatment of straw and then returned to the field, including: high temperature composting, composting with decomposing agent, thermal cracking carbonization[2, 3]. Numerous studies have shown that straw returning can improve soil fertility, soil physical structure and soil microbial community structure, and increase crop yield[4-6]. At present, there are many studies on the utilization of straw returning in saline-alkali soil treatment[7-9], but there are few studies comparing the effects of different straw returning methods on saline soil improvement[10]. Therefore, through indoor incubation experiments, this study studied the effects of applying maize straw, decomposed straw and maize straw biomass charcoal into saline soil on its physical and biological characteristics, in order to provide theoretical basis and practical guidance for promoting straw returning to improve saline soil.

\section{Materials and Methods}

\subsection{Test Materia}

The test soil was sampled from the saline soil of Jilin Songyuan. After the soil was collected, it was naturally air-dried at room temperature and passed through a $2 \mathrm{~mm}$ sieve for use. The soil sample has a $\mathrm{pH}$ value of 9.67 , an EC value of $0.274 \mathrm{mS} / \mathrm{cm}$, an alkalinity of $21.6 \%$, a soil organic carbon content of $13.9 \mathrm{~g} \cdot \mathrm{kg}^{-1}$, and a soil total nitrogen content of $2.1 \mathrm{~g} \cdot \mathrm{kg}^{-1}$. The test maize stalks were taken from the experimental field of China Agricultural University; The test straw decomposition products were prepared by adding decomposing agent after crushing straw and adjusting the $\mathrm{C} / \mathrm{N}$ ratio of $30: 1$, moisture content of $60 \%$. The above samples have been air-dried and crushed through $0.25 \mathrm{~mm}$ sieve for reserve. The tested straw biochar was prepared by drying and crushing the tested straw in oven under the condition of $75^{\circ} \mathrm{C}$ after washing, passing through 20 mesh sieve and pyrolysis for $4 \mathrm{~h}$ in vacuum muff furnace at $400^{\circ} \mathrm{C}$.

\subsection{Test Design}

In order to study the effect of different straw returning methods on saline-alkali soil improvement, it was verified by laboratory culture experiments. There are 7 treatments in the experiment: CK, no added substance; B5, adding 5\% straw biochar; B1.5, adding $1.5 \%$ straw biochar; S5, adding 5\% straw; S1.5, adding 1.5\% straw; $\mathrm{SD}$, add $5 \%$ straw rot material; SD1.5, add $1.5 \%$ straw rot material. Each treatment was repeated 3 times, and each material was mixed with the $2 \mathrm{~mm}$ sieve dry soil in the above ratio. The amount of mixed soil sample added to each flask is $200 \mathrm{~g}$ (total weight of air-dried soil and added materials), distilled water is added to $60 \%$ of the maximum water holding capacity in the field, and the cap is covered, but not completely sealed for gas exchange. 
The culture was carried out under the constant temperature of $(25 \pm 1){ }^{\circ} \mathrm{C}$, and the water was supplemented by the weighing method during the cultivation to keep the soil water content constant. After the end of the culture (day 54), the soil samples were measured for water-stable agglomerate distribution, agglomerate stability, catalase activity, urease activity, and alkaline phosphatase activity.

\subsection{Measuring items and methods}

Grading and calculation of soil aggregates: The soil agglomerates were classified by wet sieve method. Three soil samples were taken for each treatment, $100 \mathrm{~g}$ each, and the soil samples were soaked in deionized water for $20 \mathrm{~min}$ and then poured into a sieve. The sieve aperture is $2,0.25$ and $0.053 \mathrm{~mm}$ from top to bottom, and is sieved at a frequency of $20 \mathrm{r} / \mathrm{min}$ for $15 \mathrm{~min}$ using agglomerate analyzer. Soil samples are divided into $<0.053 \mathrm{~mm}, 0.053-0.25 \mathrm{~mm}, 0.25 \mathrm{~mm} \sim 2 \mathrm{~mm}$ and $>2$ $\mathrm{mm}$. The obtained agglomerates are transferred to an aluminum box, dried at $50{ }^{\circ} \mathrm{C}$. The average weight diameter (MWD) and geometric mean diameter (GMD) were calculated according to formula (1) and formula (2) according to the aggregates data obtained after wet sieving.

$$
\begin{gathered}
M W D=\sum_{i=1}^{n} X_{i} W_{i} \\
G M D=\sum_{i=1}^{n}\left(\ln X_{i}\right) W_{i}
\end{gathered}
$$

Soil alkalization degree: NH4OAc-NH4OH flame photometry [11].

Soil urease activity: determined by indophenol blue colorimetric method[12], expressed in milligrams of NH3-N per gram of dry soil after 24 hours of culture at $37^{\circ} \mathrm{C}$.

Soil catalase activity: permanganate titration method was used to determine[12], expressed in milliliters of 0.1 $\mathrm{N}$ potassium permanganate per gram of dry soil after 20 minutes.

Soil alkaline phosphatase activity: determined by the phenylphosphonium phosphate method[12], expressed as millimoles of phenol released per gram of dry soil after 24 hours of culture at $37^{\circ} \mathrm{C}$.

\subsection{Data Analysis}

The test data was recorded and sorted by Excel. The data was analyzed by ANOVA using SPSS 22, and multiple comparisons were performed by LSD method $(\alpha=0.05)$. The data was plotted by Origin 8.0 software.

\section{Results and analysis}

3.1 Effect of Different Straw Returning Ways on Distribution of Water Stability Aggregates in Saline-alkali Soil
Aggregates are the basic unit of soil structure, which are closely related to the conservation and supply of soil nutrients. As shown in Figure 1, both $\mathrm{S}$ and SD significantly increased the content of $>2 \mathrm{~mm}$ size agglomerates, large agglomerates $(0.25-0.2 \mathrm{~mm})$ and microaggregates $(0.053-0.25 \mathrm{~mm})$ compared to $\mathrm{CK}$, where $\mathrm{S}$ pairs $>2 \mathrm{~mm}$ particle size aggregates and large agglomerates $(0.25-0.2 \mathrm{~mm})$ content is better than $\mathrm{SD}$; B significantly reduced the content of soil macroaggregates $(0.25-0.2 \mathrm{~mm})$; all treatments significantly increased the content of micro-aggregates (0.053-0.25 mm); all treatments reduced the content of clay $(<0.053 \mathrm{~mm})$, and all treatments except B significantly decreased, of which S1.5 and S5 decreased the most, $38.3 \%$ and $33.7 \%$ respectively.

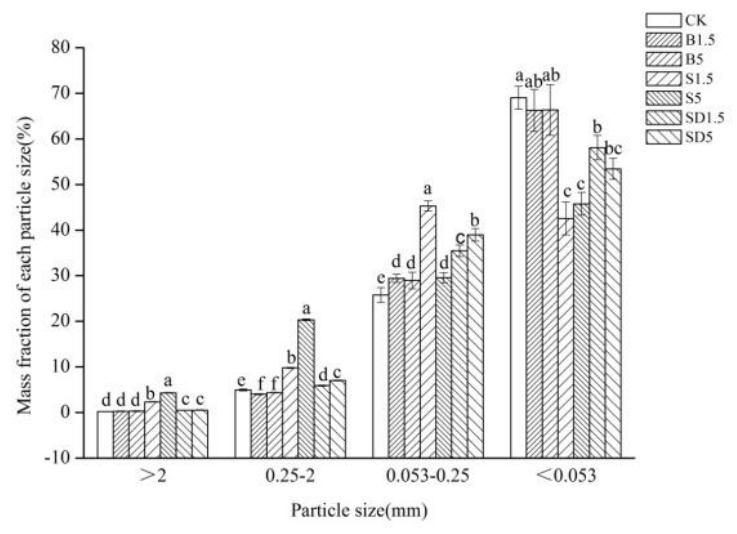

Fig.1. Effect of different treatments on soil aggregate content

Note: Error bars represent standard errors. Different letters indicate significant differences between treatments $(P<0.05)$, The same below

\subsection{Effect of different straw returning methods on the stability of saline-alkali soil aggregates}

Mean weight diameter (MWD) and geometric mean diameter (GMD) are important indexes for evaluating the stability of soil aggregates. As shown in Table 1, compared with CK, MWD and GMD of B had no significant difference. The other treatments significantly increased MWD and GMD, with the order of increase being $\mathrm{S} 5>\mathrm{S} 1.5>\mathrm{SD} 5>\mathrm{SD} 1.5$. The increase rates were $182.4 \%, 83.1 \%$, 30.9\%, 18.4\% (MWD); 92.7\%, 52.4\%, $23.2 \%, 14.6 \%$ (GMD), respectively.

Tab1 Effect of different treatments on the stability of soil aggregates

\begin{tabular}{ccc}
\hline Treatment & MWD(mm) & GMD(mm) \\
\hline CK & $0.136 \pm 0.007 \mathrm{~d}$ & $0.082 \pm 0.003 \mathrm{~d}$ \\
B1.5 & $0.131 \pm 0.010 \mathrm{~d}$ & $0.084 \pm 0.008 \mathrm{~d}$ \\
B5 & $0.135 \pm 0.002 \mathrm{~d}$ & $0.083 \pm 0.008 \mathrm{~d}$ \\
S1.5 & $0.249 \pm 0.005 \mathrm{~b}$ & $0.125 \pm 0.006 \mathrm{~b}$ \\
S5 & $0.384 \pm 0.006 \mathrm{a}$ & $0.158 \pm 0.006 \mathrm{a}$ \\
SD1.5 & $0.161 \pm 0.011 \mathrm{c}$ & $0.094 \pm 0.004 \mathrm{~cd}$ \\
SD5 & $0.178 \pm 0.007 \mathrm{c}$ & $0.101 \pm 0.005 \mathrm{c}$ \\
\hline
\end{tabular}




\subsection{Effect of different straw returning methods on alkalinity of saline-alkaline soil}

Exchangeable sodium percentage (ESP) is the percentage of soil exchangeable sodium in cation exchange capacity. As shown in Table 2, all treatments significantly reduce ESP in soil, with B5 decreasing by $41.3 \%$. The decrease of ESP in all treatments increased with the increase of the dosage.

Table 2 Effects of different treatments on soil ESP

\begin{tabular}{cc}
\hline Treatment & $\mathbf{E S P}(\%)$ \\
\hline CK & $0.206 \pm 0.006 \mathrm{a}$ \\
B1.5 & $0.147 \pm 0.002 \mathrm{~d}$ \\
B5 & $0.121 \pm 0.003 \mathrm{e}$ \\
S1.5 & $0.182 \pm 0.003 \mathrm{~b}$ \\
S5 & $0.155 \pm 0.005 \mathrm{~d}$ \\
SD1.5 & $0.167 \pm 0.005 \mathrm{c}$ \\
SD5 & $0.147 \pm 0.004 \mathrm{~d}$ \\
\hline
\end{tabular}

\subsection{Effects of Different Straw Returning Ways on Activities of Saline-alkali Soil Enzymes}

Soil urease is one of the most important hydrolases in soil. Its activity can reflect the nitrogen utilization of soil. As shown in Table 3, compared with CK, B significantly reduced the activity of soil urease, and the other treatments significantly increased the activity of soil urease, of which S5 increased the most, which was $39.6 \%$. The soil urease activity of each treatment was proportional to the addition amount.

Soil catalase promotes the decomposition of hydrogen peroxide in the soil and prevents hydrogen peroxide from harming soil organisms. As shown in Table 3, only B1.5 and B5 significantly increased soil catalase activity, with an increase of $34.5 \%$ and $24.1 \%$, respectively. S and SD reduced soil catalase activity to a different extent, and SD decreased significantly.

Soil alkaline phosphatase plays an important role in improving soil phosphorus availability. Soil alkaline phosphatase activity was significantly increased by $\mathrm{S} 1.5$, S5 and SD5, with an increase of $19.4 \%, 37.1 \%$ and $36.3 \%$ respectively. Soil alkaline phosphatase activity of B1.5 and B5 decreased compared with $\mathrm{CK}$, but the difference was not significant.

Table 3 Effects of different treatments on soil enzyme activities

\begin{tabular}{cccc}
\hline Treatment & Urease & Catalase & $\begin{array}{c}\text { Alkaline } \\
\text { phosphatase }\end{array}$ \\
\hline CK & $2390 \pm 122 \mathrm{c}$ & $0.50 \pm 0.03 \mathrm{~b}$ & $12.4 \pm 2.5 \mathrm{~b}$ \\
B1.5 & $1720 \pm 107 \mathrm{~d}$ & $0.68 \pm 0.04 \mathrm{a}$ & $13.1 \pm 2.2 \mathrm{~b}$ \\
B5 & $2021 \pm 166 \mathrm{~d}$ & $0.62 \pm 0.03 \mathrm{a}$ & $12.2 \pm 1.4 \mathrm{~b}$ \\
S1.5 & $2717 \pm 119 \mathrm{~b}$ & $0.42 \pm 0.03 \mathrm{c}$ & $14.8 \pm 2.3 \mathrm{ab}$ \\
S5 & $3337 \pm 130 \mathrm{a}$ & $0.44 \pm 0.04 \mathrm{bc}$ & $17.0 \pm 1.7 \mathrm{a}$ \\
SD1.5 & $2637 \pm 160 \mathrm{bc}$ & $0.36 \pm 0.02 \mathrm{c}$ & $12.2 \pm 1.9 \mathrm{~b}$ \\
SD5 & $2775 \pm 130 \mathrm{~b}$ & $0.21 \pm 0.03 \mathrm{~d}$ & $16.9 \pm 1.9 \mathrm{a}$ \\
\hline
\end{tabular}

\section{Discussion}

Soil aggregates are an important part of soil and the material basis of soil fertility, which is closely related to the transmission and transmission of water, fertilizer, gas and heat in soil and microbial species and activities [13]. The effects of different straw returning methods on soil aggregates have become a research hotspot in recent years. The existing researches show that fresh straw and decomposed straw returning to the field can significantly increase the content of soil $>0.25 \mathrm{~mm}$ size aggregates, reduce the content of soil clay powder $(<0.053 \mathrm{~mm})$, and fresh straw is more conducive to the formation of soil water stable aggregates than decomposed straw $[14,15]$. The reason is that when fresh straw is decomposed in soil, it will form polysaccharides with strong ability of cementing soil granules[16]; in addition, when fresh straw is imported into soil, it will become a place for microbial activities and form aggregate core[17]. This is consistent with the results of this study. However, the effect of straw biochar on soil aggregates is controversial Liu[18] found that when the amount of biochar applied was $40 \mathrm{t}^{\circ} \mathrm{ha}^{-1}$, the MWD of soil water-stable aggregates increased by $28.02 \%$; Dai[19] found that MWD decreased by $18.9 \%-43.2 \%$ during the three years of biochar application to the soil; while Hou[20] found that single application of biochar had no significant effect on soil GMD and MWD, which was consistent with the results of this study. The reason may be that the organic carbon in biochar is mainly inert carbon, which is low in the utilization rate of microbial decomposition, and does not produce sticky substances in the decomposition process to promote the formation of agglomerates[21, 22].

ESP is an important indicator for evaluating the alkalinity of soil. The larger the ESP, the worse the soil quality. At present, there are few studies on the effect of straw returning on soil alkalization. Fan[23] believes that organic acids in the process of decomposition of organic matter in straw will release cations and replace $\mathrm{Na}^{+}$on soil colloids, thus reducing soil ESP; Chen[24], Yu[25] research found that biochar can reduce ESP of saline soil, on the one hand, the surface of biochar is rich in exchangeable $\mathrm{Ca}^{2+}$ and $\mathrm{Mg}^{2+}$; on the other hand, biochar increases soil porosity by virtue of its porous structure, which makes $\mathrm{Na}^{+}$more easily removed by leaching. This study also proves that all kinds of straw returning methods can reduce ESP in saline soil.

Many studies have shown that straw returning has a significant impact on soil enzyme activity. Among them, there are many studies on the effects of fresh straw and decomposed straw on soil enzyme activity, and the mechanism is thoroughly analyzed. Tang[26] believed that straw returning could increase a lot of energy for soil microorganisms and promote the biological cycle of soil substances, thereby improving soil enzyme activity; some scholars believe that straw can affect soil enzyme activity by adjusting soil carbon-nitrogen ratio, temperature and water content $[27,28]$. At present, there are few studies on the effect of straw biochar on soil enzyme activity. Baileya[29] studies have shown that biochar binds to the substrate of the enzymatic reaction 
and inhibits the enzymatic reaction, thereby inhibiting the enzyme activity. At the same time, they believe that the effect of biochar on soil enzyme activity is highly variable, depending on the nature of the target substrate. In this study, the activities of soil urease and alkaline phosphatase were significantly increased by returning fresh straw and decomposed straw to field, and the increase was positively correlated with the addition amount, which was consistent with the results of $\mathrm{Lu}$ [30], Yang[31]. The study observed that fresh straw and decomposed straw returning significantly reduced soil catalase activity, which may be related to the length of culture[32]; The straw biochar significantly increased the soil catalase activity, but significantly reduced the soil urease activity, which is contrary to the results of Pan[33], which may be related to the different preparation conditions, structural properties[34] and soil properties[35].

\section{References}

1. Department of Science and Technology Education, Agricultural Ecology and Resource Protection Station of the Ministry of Agriculture. National Rural Renewable Energy Statistics Summary Table 2016 [Z]. Beijing: China Agriculture Press, (2016).

2. F.Y. Cao, Changes of organic acids, energy and structure of straw and soil during decomposition [D]. Northwest University of Agriculture and Forestry Science and Technology, (2016).

3. G.X. Pan, A.Q. Li, X.Y. Liu, et al. Industrialization of pyrolysis biomass charcoal: a new approach to banning burning of straw and green agriculture [J]. Science and Technology Report, (2015), 33 (13): 92101.

4. S. Chen, X.Q. Ding, Z.K. Zhu, etc. Effects of straw returning on transformation of exogenous nitrogen in soil and microbial response [J]. Environmental Science, (2017), 38 (04): 1613-1621.

5. C.R. Meng, R.X. Bai, P.H. Yang, et al. Effects of straw returning on drip irrigation maize production and soil microorganisms in arid areas $[\mathrm{J}]$. Xinjiang Agricultural Science, (2018), 55 (12): 2251-2260.

6. W.J. Xie, L.F. Wu, Y.P. Zhang, et al. Effects of straw application on coastal saline topsoil salinity and wheat yield trend[J].Soil \& Tillage Research, (2017), 169:1-6.

7. T. Liu, B.T. Wang, H.J. Xiao, et al. Differentially improved soil microenvironment and seedling growth of Amorpha fruticosa by plastic, sand and straw mulching in a saline wasteland in northwest China[J]. Ecological Engineering,(2018),122.

8. L. Huo, H.C. Pang, Y.G. Zhao, et al. Buried straw layer plus plastic mulching improves soil organic carbon fractions in an arid saline soil from Northwest China[J]. Soil \&Tillage Research,(2017),165.

9. Y.B. Mi, G.S. Yang, R.J. Yao, etc. Effects of different measures on respiration, conductivity and organic carbon in coastal saline soil [J].Journal of Soil Science, (2016),53(03): 612-620.

10. D. Yang, X.J. Li, X.X. Kong. Influence of Different Straw Returning Methods on Water and Salt Movement of Coastal Saline Soil[J].Research of Soil and Water Conservation,(2017),24(06):74-78.

11. S.D. Bao. Analysis of soil agrochemical [M]. Beijing: China Agricultural Press, (2000), 25 114.

12. S.Y. Guan. Soil enzymes and research methods [M]. Beijing: Agricultural Press, (1986).

13. Q.K. Wang, S.L. Wang. Formation and stabilization mechanism of soil aggregates and influencing factors [J]. Soil Bulletin, (2005), 03: 415-421.

14. C.X. Liu, Y. Huang. Effects of Saline-AlkaliTolerant bacteria and organic materials on aggregate formation of saline-alkali soil [J].Soil, (2010),42(01): 111-116.

15. F.S. Gao, Z.X. Cui, R.W. Fan, etc. Improvement of saline-alkali soil by organic materials $[\mathrm{J}]$. Soil Bulletin, (1997),01: 10-12.

16. M.E. Zou, Q.F. Chu. Effect of polysaccharide in straw returning [J]. Soil fertilizer, (1992), 04: 16-18.

17. J.D. Jastrow. Soil aggregate formation and the accrual of particulate and mineral-associated organic matter $[\mathrm{J}]$. Soil Biology and Biochemistry, (1996),28(4).

18. Z.X. Liu, X.M. Chen, Y. Jing, et al. Effects of biochar amendment on rapeseed and sweet potato yields and water stable aggregate in upland red soil[J]. Catena,(2014),123.

19. H.C. Dai, Y.Q. Chen, K. Chang, et al. Water-stable aggregates and carbon accumulation in barren sandy soil depend on organic amendment method: A threeyear field study[J]. Journal of Cleaner Production,(2019), 212.

20. X.N. Hou, H. Li, L.B. Zhu, et al. Effects of biochar and straw addition on aggregate composition and organic carbon distribution of Shajiang black soil [J]. Agricultural Science of China, (2015), 48 (04): 705712 .

21. D. Tian. Response of carbon budget of farmland ecosystem to straw and biochar returning [D]. Southwest University, (2017).

22. L.L. Ye, C.H. Wang, H. Zhou, et al. Effects of adding biomass black carbon on the structural stability of red soil [J]. Soil, (2012), 44 (01): 62-66.

23. F. Fan, Q.G. Zhang, F.H Hou, et al. Effects of corn straw isolation layer on alkalization characteristics and nutrient status of saline-alkali soil in the West Liaohe River Basin [J]. Journal of Soil and Water Conservation, (2013), 27 (03): 131-137.

24. Y.H. Chen, S.Q. Liao, Y.M. Li, et al. Effects of biochar and gardening waste compost on protected vegetables: I. Soil physical and chemical properties and yield [J]. Journal of Agricultural Environmental Sciences, (2015), 34 (05): 913-919. 
25. Y. Yu, J. Liu, C.M. Liu, et al. Effect of organic materials on the chemical properties of saline soil in the Yellow River Delta of China. Frontiers of Earth Science,(2015),9:259-267.

26. S.D. Tang. Soil Biological Effects of Direct Returning Crop Straw to Field [J]. Journal of Soil Science, (1980), 02: 172-181.

27. GIANFREDAL, RAO MA, PIOTROWSKA A, et a1. Soil enzyme activities as affected by anthropogenic alterations: Intensive agricultural practices and organic pollution $[\mathrm{J}]$. Sciences of the Total Environment, (2005), 341: 265 - 279.

28. BANDICK AK, DICK RP. Field management effects on soil enzyme activities [J]. Soil Biology \& Biochemistry, (1999), 31(11): 1471 - 1479.

29. Baileya V L, Fanslera S J, Smithb J L, et al. Reconciling apparent variability in effects of biochar amendment on soil enzyme activities by assay optimization [J]. Soil Biology and Biochemistry, (2011),43(2):296-301.

30. Y.Q. Lu, A.N. Zhu, J.B. Zhang, et al. Effects of notillage and straw returning on soil enzyme activity and microbial community [J]. Soil Bulletin, (2014), 45 (01): 85-90.

31. X.H. Yang. Effects of decomposed corn straw on soil environment, quality and yield in Cucumber Root Zone [D]. Shandong Agricultural University, (2013).

32. W. Zhang, J.P. Gong, J.G. Liu. Effects of straw returning on soil enzyme activities in continuous cropping cotton fields [J]. Journal of Ecological Environment, (2011), 20 (05): 881-885.

33. Q.L. Pan, T. Song, K. Chen, et al.Effects of biochar and carbon-based fertilizers on biological activity of brown soil for 6 years[J].Journal of North China Agricultural University,(2016),31 (03): 225-232.]

34. X.Y. Jiang. Study on Preparation and characterization of sludge-based biochar and application of soil improvement [D]. Harbin University of Technology, (2014).

35. J. Shang, Z.C. Geng, X.X. Chen, et al. Effects of biochar on soil enzyme activity and Millet Yield [J]. Agricultural Research in Arid Areas, (2015), 33 (02): $146-151+158$ 